DOI: $10.12731 / 2227-930 X-2017-1-28-37$

\title{
INTERACTIVITY OF THE MODERN AUTOMATED SYSTEMS OF THE HELP TO THE DRIVER
}

\section{Vasyugova S.A., Nikolaev A.B.}

In this article the current technologies in the field of intelligent transportation systems are investigated. The latest systems on control of the safe movement on roads are considered. The analysis of the systems of the help to the driver implemented in cars is carried out. The system concept of the help to the driver of «System help» is offered. Algorithms of work of this system which is based on the principles of interactivity and interaction are investigated. By results of researches experiment on quality of work of system concept of «System help» is made.

Keywords: automation; transport; car; System help; ITS; controller; algorithm; LEGO.

\section{Introduction}

The movement safety issue on roads already long time remains priority worldwide. Processes of ensuring reliable and safe movement on roads affect various areas of road infrastructure, technical means, science and education in general. The package of measures for identification of factors which are capable to increase quality of work of system of regulation of traffic and quality of functioning of internal system of the vehicle is undertaken.

\section{Modern innovations in ITS}

Today there is a number of innovative solutions on safety on roads. These decisions affect two main areas: external (extends to road transport infrastructure) and internal (the implemented systems increasing safety of use of the vehicle).

To external it is possible to carry:

- installation of adaptive traffic lights (incorporate the sensors which are reading out density and flow rate, meteoconditions 
and other factors then information goes to uniform control center on a wireless communication);

- means of automatic fixing of violations of the rules of traffic traffic regulations (probing devices and means of a photo of fixing and video of fixing of a road flow and separate elements);

- electronic information displays (reflect a situation in roads in the mode onlayn 6 the high-speed mode, weather conditions, jams on roads and a way of a detour, an arrival time to this or that point on the map, etc.);

- detectors of a transport flow (are equipped with several sensors of different type: a microwave radar for measurement of speed, the ultrasonic detector for an assessment of dimensions and classification of vehicles by classes and the multichannel infrared detector for ensuring calculation of cars and determination of intensity of the movement);

- system of automatic lighting;

- road controllers and automatic road meteorological stations [1];

It is possible to carry to internal innovative solutions:

- system of detection of pedestrians;

- system of recognition of route signs;

- system of deduction of a lane;

- monitoring system of degree of fatigue of the driver;

- system of the auto pilot;

- system of the automatic parking, etc.

All above-mentioned internal systems are similar among themselves in the constituting components and the interacting nodes. Sensors of collection and scanning of information of an external situation, cameras and radars (lidars) are the cornerstone of such systems. The onboard computer (controller) which carries out all main computing functions and management functions by all system [2] acts as control center of such systems.

However the modern implemented technologies not always meet the requirements which were set earlier by it. Some systems have a limited scope. Not all systems are capable to guarantee the high level of 
protection of the driver and the car against possible incidents. Systems, which possess high adaptability to surrounding conditions and a capability independently to make decisions, have the greatest efficiency.

Within this article, authors have researched modern systems of cars and their possibility of the automated work. During researches and experiments the conclusion has been drawn that the most effective are those systems which possess a capability quickly to adapt to changes in environment and a possibility of communication between the interacting elements. Such systems are capable to increase quality of work of the car and safety of its use.

\section{The automated system «System help»}

The principle of work of this system consists in an assessment of the surrounding situation by collection of information arriving from external sensors on the onboard computer of the vehicle and decision making on impact on the hardware executive mechanisms, and also, to informing all active participants of traffic (fig. 1). Active participants of movement are understood as those vehicles with which physical contact is possible (collision, a contact etc.).

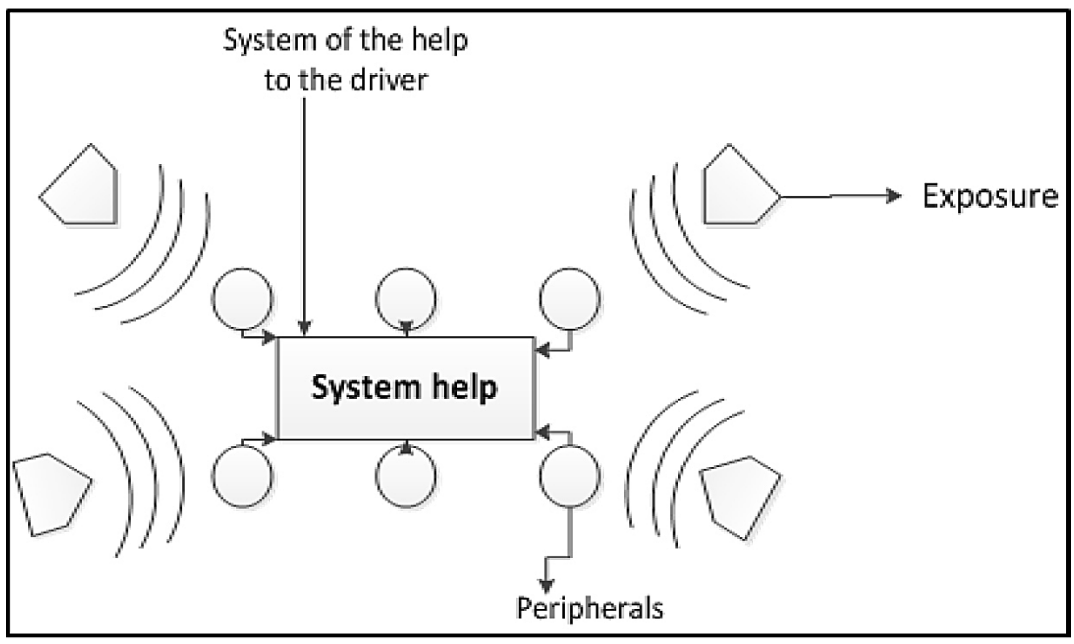

Fig. 1. Work of the system «System help» 
The system makes the decision, analyzing all arriving data. Therefore influences, as the hardware executive mechanisms, on which it is established and on the hardware executive mechanisms of active participants (provided that all the hardware are equipped with this system), if it is necessary (fig. 2). The principle of interaction of one system happens to another on the «System - to - System» model. Interaction happens only to systems of one type. The system of the car equipped with "System help" can address system of the car with the same system of $n$-times (where $n=1 \ldots \infty$ ).

Depending on the existing danger, it is possible to allocate 3 ways of interaction between systems:

1. Giving of the warning signal or the message on the instrument panel of the car (in fig. $\mathbf{2}$ it is represented as "!!!").

2. Projection of the warning sign or the corresponding message on a rear screen of the car (in fig. $\mathbf{2}$ it is represented as "Stop").

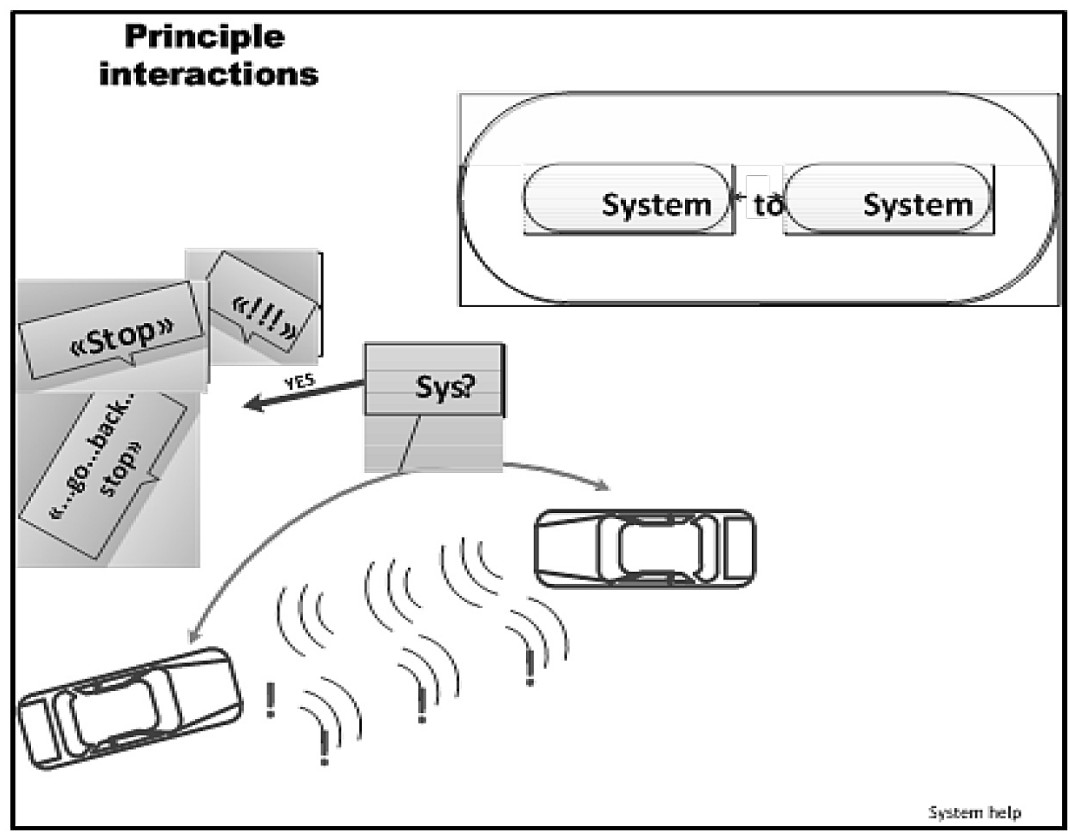

Fig. 2. Principle of interaction between systems (Sys-a condition of verification of system like "System help") 
3. Giving of the operating signals on the operating hardware mechanisms (in fig. $\mathbf{2}$ as «go ... back ... stop»).

\section{Interactivity of the system «System help»}

Advantage of "System help" consists in ability of systems of cars to the automated interactivity. At danger detection the system initially informs the driver on the arisen hindrances and if the driver for any reasons ignores signals of system, "System help" transfers work of the car to an off-line mode.

At an off-line mode of work the system interrogates participants of the movement who are in the radius of action of system and, at an affirmative answer on request, makes connection to system of other car (fig. 3).

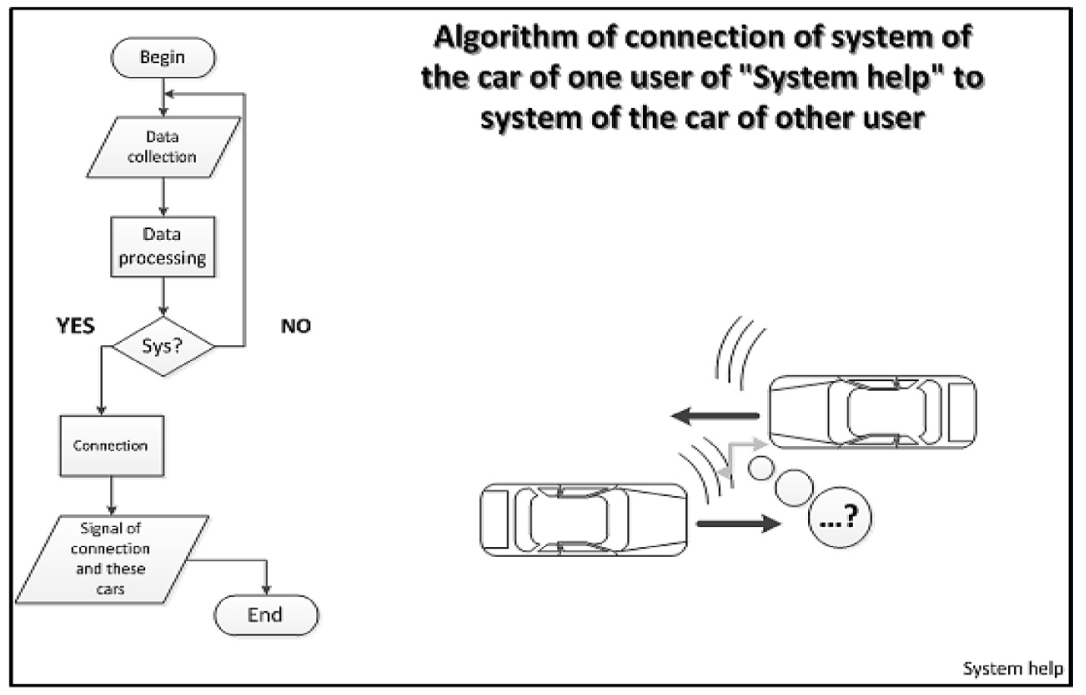

Fig. 3. Algorithm of connection of one system "System help" to another (Sys-a condition of verification of presence of system like "System help")

After connection of one system to another, on the screen of the instrument panel it is given the corresponding signal and the message on connection and these cars, which participate in "communication" 
(serial number of the car, model and make of the car and identification number in the «System help» system).

In figure 4 (fig. 4) the algorithm of interactivity between systems on which interaction between participants of traffic is step by step described is presented. The element $\mathrm{S}$ is check of the contacting object on existence of the system «System help». Element W - is danger condition.

\section{Experiment on interaction}

Within researches, experiment on interaction of systems has been delivered. Testing and the analysis of influence on changes of traffic of the used principles of the «System help» system was held.

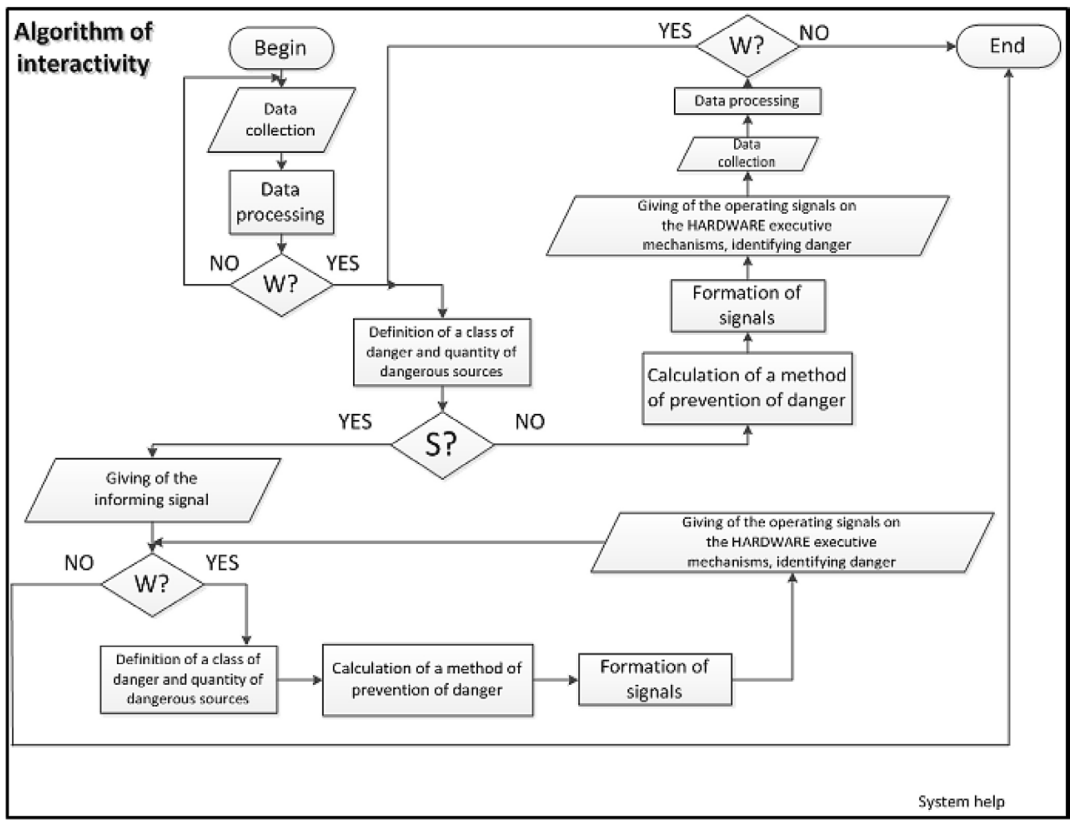

Fig. 4. Algorithm of interactivity

In experiment three robots (fig. 5) were used. Two robots are created on the basis of the designer LEGO MINDSTORMS complex, with use of the EV3 and NXT controller. Programs with use of a programming 
environment of LEGO MINDSTORMS Education EV3 and LEGO MINDSTORMS NXT were developed for each robot.

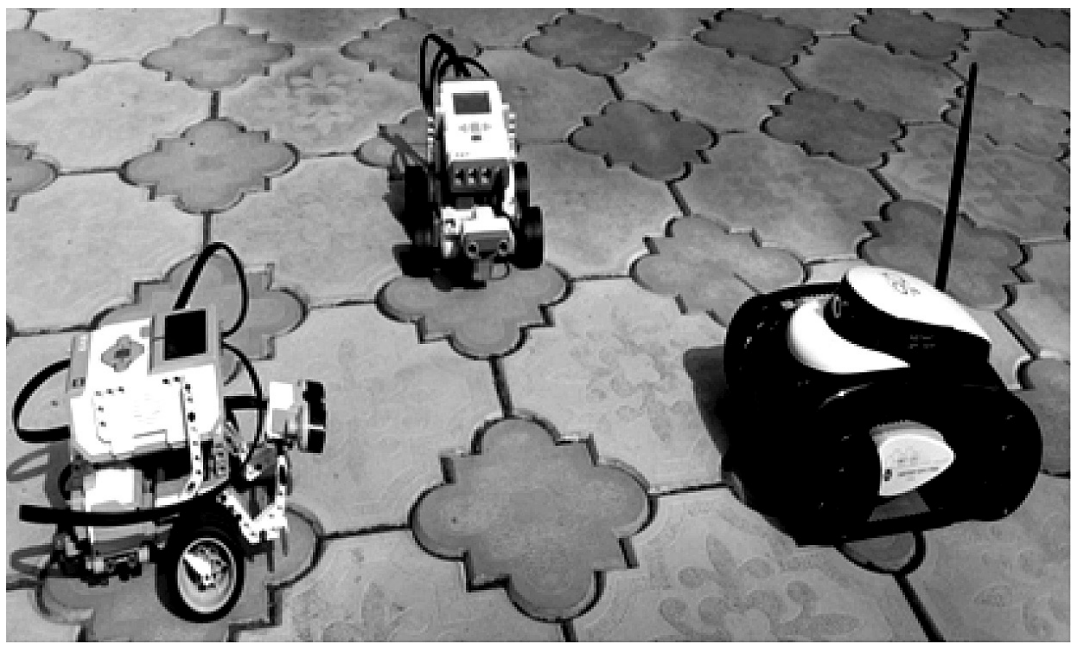

Fig. 5. Experiment on interaction

As the third object the i-Spy Tank robot which was used as system which isn't equipped with the principles of "System help" has been used. It is played a role of the object creating hindrances for two other robots (fig. 6). It was necessary for additional check of level of readiness of system to react to numerous external hindrances.

LEGO robots worked in an off-line mode. For their movement the trajectory imitating journey of the intersection has been constructed. The i-Spy Tank robot received management remotely from the tablet, using the created Wi-Fi network for connection.

During numerous changes of a trajectory of the movement of the i-Spy Tank robot for the purpose of creation of new hindrances, LEGO robots successfully avoided collision with each other, being based on interactivity and timely transfer of the informing and managing signals. As a result of carrying out 10 experiments, only in one case there was a collision of the LEGO robot with i-Spy Tank. It has been connected with purposefully fast changing of a trajectory of i-Spy Tank. 


\section{Main working elements of the robot}

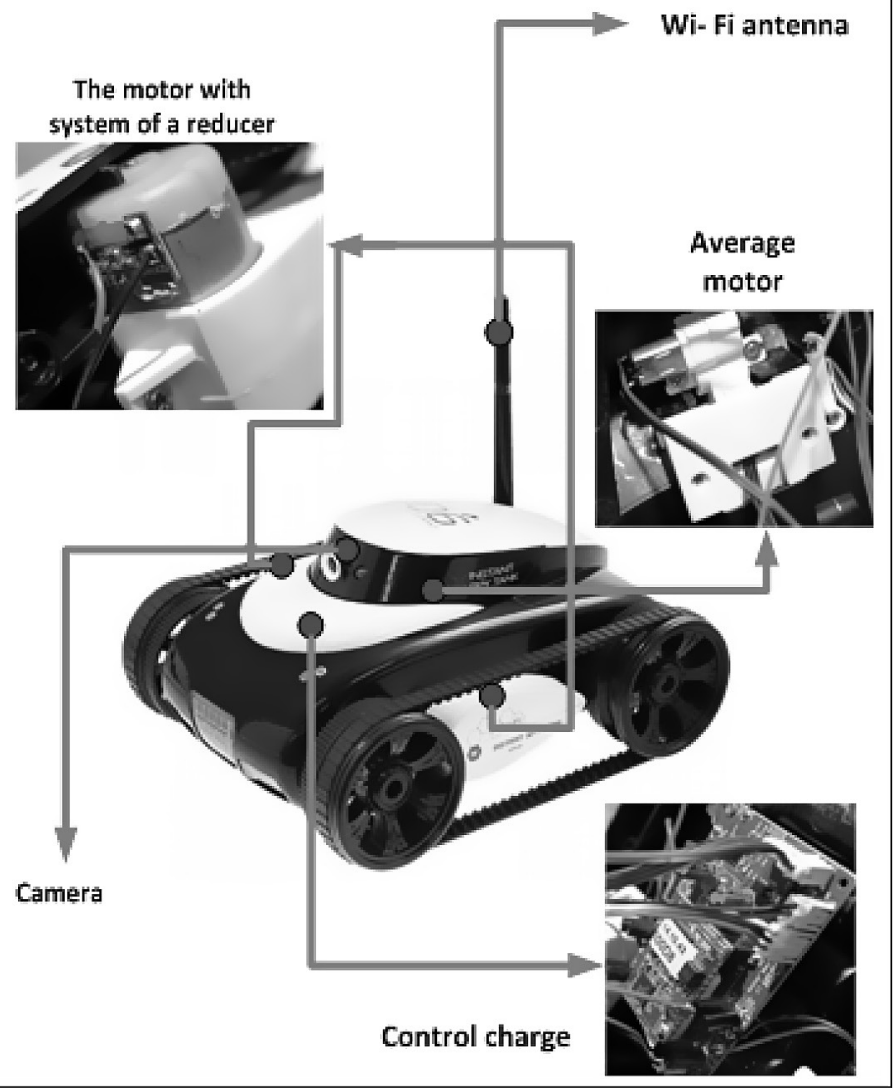

Fig. 6. Robot i-Spy Tank

\section{Conclusion}

Automation the processes of the car is very necessary and important area in automotive industry. Traffic safety directly depends on modernization of this area. 
The system «System help» as has shown experiment on interaction, is capable to provide comfortable and safe use of the car, and also, to help the driver with difficult and dangerous situations on roads, making autonomous decisions.

\section{References}

1. www.json.ru/ru/markets_research/analytical_reports

2. Vasyugova S.A., Nikolaev A.B. Analysis and research of opportunities of system of the help to the driver of "SYSTEM HELP". In the world of discoveries. Collection "Natural and Technical Science", No. 4 (64). Scientific and Innovative Center publishing house, Krasnoyarsk, 2015. The magazine is included in the List of VAK of the leading reviewed scientific magazines.

3. Vasyugova S.A., Nikolaev A.B. Analysis and research of opportunities of system of the help to the driver of "SYSTEM HELP". In the world of discoveries. Collection "Natural and Technical Science", No. 4 (64). Scientific and Innovative Center publishing house, Krasnoyarsk, 2015.

4. Vasyugova S.A., Nikolaev A.B. Job analysis of system of the help to the driver. Questions of modern technical science: new view and new decisions. The collection of scientific works following the results of the international scientific practical conference, No. 2. Yekaterinburg, 2015.

5. Autosar: Automotive open system architecture. http://www. autosar. org/

6. CAMP Vehicle Safety Communications Consortium. Vehicle safety communications project task 3 final report, Mar. 2005. Online: http:// www.intellidriveusa.org/documents/ vehicle-safety.pdf

7. United States Congress House. Committee on Transportation, \& Infrastructure. Subcommittee on Highways and Transit. How Autonomous Vehicles Will Shape the Future of Surface Transportation: Testimony of the Honorable Kirk Steudle, Director, Michigan Department of Transportation, House of Representatives, One Hundred Thirteenth Congress, first session, November 19, 2013. 
8. Martelle S. "Self-driving Cars and the Liability Issues They Raise." Project Consumer Justice. May 2012. Online. http://www.protectconsumerjustice.org/self-driving-cars-and-the-liability-issuesthey-raise.html

9. Simpson J.M. "DMV's Autonomous Vehicle Regulations Must Protect Users' Privacy." Consumer Watchdog. March 2014. Online. http://www.consumerwatchdog.org/resources/dmvtestimoIndustry Shift Applied Innovation Review 22 Issue 1 June 2015 ny031114.pdf

10. Mui C. "Will Auto Insurers Survive their Collision with Driverless Cars?” Forbes. March 2013. Online. http://www.forbes.com/sites/ chunkamui/2013/03/28/will-auto-insurers-survive-their-collisionwith-driverless-cars-part-6/

11. Boulton Clint. "Nissan Lays Out Roadmap for Autonomous Cars." The Wall Street Journal Blog. July 2014. Online. http://blogs.wsj. com/cio/2014/07/17/nissan-lays-out-road-map-for-autonomouscars/

12. Weiss C.C. "Toyota Details Its Automated Highway Driving System." Gizmag. October 2013. Online. http://www.gizmag.com/toyota-automated-highway-driving/29378/

13. Automated Vechile Institute. 2014. Online. http://www.usfav.com/ currentAV.html

14. Silberg Gary. Self-Driving Cars: Are We Ready? KPMG. October 2013.

\section{DATA ABOUT THE AUTHORS}

Vasyugova Svetlana Alekseevna, Graduate Student of Automated Control Systems Chair

State Technical University - MADI

64, Leningradsky prospekt, Moscow, 125319, Russian Federation vas715@gmail.com

Nikolaev Andrey Borisovich, Honoris Causa, Doctor of Technical Sciences, Professor, Head of Department

State Technical University - MADI

64, Leningradsky prospekt, Moscow, 125319, Russian Federation nikolaev.madi@mail.ru 